\title{
EXPRESSÃO DA PROTEÍNA P53 NO ADENOCARCINOMA GÁSTRICO: CORRELAÇÃO CLÍNICA, ANATOMOPATOLÓGICA E SIGNIFICÂNCIA PROGNÓSTICA
}

\section{P53 EXPRESSION IN GASTRIC ADENOCARCINOMA: CLINICOPATHOLOGICAL CORRELATIONAND PROGNOSTIC SIGNIFICANCE}

\author{
Frederico Theobaldo Ramos Rocha, TCBC-AL ${ }^{1}$ \\ Laercio Gomes Lourenço, $\mathrm{ACBC}-\mathrm{SP}^{2}$ \\ Mário Jorge Jucá, TCBC - AL. ${ }^{3}$ \\ Antenor Teixeira Leal ${ }^{4}$ \\ Antônio Mário Duarte Coelho da Paz
}

\begin{abstract}
RESUMO: Objetivo: Avaliar a expressão da proteína p53 no adenocarcinoma gástrico e correlacioná-la com variáveis clínicas e anatomopatológicas, tais como: idade, sexo, infiltração da parede gástrica (T), tipo histológico (Laurén), grau de diferenciação histológica, comprometimento linfonodal, estadiamento (TNM) e sobrevida. Método: Foram analisados os registros médicos e reestudadas as lâminas de peças cirúrgicas de 45 doentes com adenocarcinomas gástricos submetidos à gastrectomia parcial e total no Serviço de Cirurgia Oncológica da Santa Casa de Misericórdia de Maceió-AL e no Hospital Universitário da Universidade Federal de Alagoas, no período de 1991 a 2002. A expressão da proteína p53 foi avaliada pelo método imunohistoquímico com o anticorpo monoclonal DO-7 e comparada com idade, sexo, infiltração na parede gástrica, tipo histológico, grau de diferenciação, comprometimento linfonodal, estadiamento e sobrevida. Resultados: Dos 45 doentes, 27 eram do sexo masculino (60\%). A média das idades foi 53,9 anos (26- 75 anos), e mediana de 57 anos. Em 40 doentes $(88,9 \%)$ o tumor foi classificado como bem diferenciado. Quanto à infiltração na parede gástrica, em 28 doentes $(62,2 \%)$ foram classificados como profundos. Em 25 doentes $(55,6 \%)$ não havia comprometimento linfonodal. O estudo histológico revelou que 29 doentes $(64,4 \%)$ apresentavam tumores classificados como tipo intestinal de Laurén. O estadiamento TNM demonstrou que $33(73,3 \%)$ doentes apresentavam tumores avançados. Quanto à expressão da p53, 18 doentes (40\%) foram considerados positivos. O tempo médio de seguimento foi de 1020,4 dias (63 - 3920 dias) e mediana de 798 dias. Trinta e um (68,9\%) doentes evoluíram para óbito. As variáveis: idade, estadiamento, comprometimento linfonodal e infiltração do tumor na parede gástrica, foram fatores prognósticos relacionados à sobrevida com significado estatístico $(\mathrm{p}<0,05)$. Não houve correlação estatística significativa da proteína p53 com as variáveis estudadas. A análise estatística multivariada identificou apenas o comprometimento linfonodal como fator prognóstico independente. Conclusões: Os autores concluíram que dezoito $(40 \%)$ dos doentes expressaram a reação imunohistoquímica para p53. Não houve correlação estatística significativa da expressão da proteína p53 com os fatores prognósticos estudados. A expressão da proteína p53 não foi fator prognóstico independente.
\end{abstract}

Descritores: Adenocarcinoma gástrico; Proteína p53; Imunohistoquímica; Prognóstico.

1. Mestre em Gastroenterologia Cirúrgica pela Escola Paulista de Medicina - UNIFESP; Cirurgião Oncologista da Seção de Oncologia da Santa Casa de Misericórdia e do Hospital Escola Dr. José Carneiro, Maceió - AL.

2. Prof. Adjunto da Disciplina de Gastroenterologia Cirúrgica da Escola Paulista de Medicina - UNIFESP.

3. Prof. Adjunto da Disciplina de Cirurgia Geral da Universidade Federal de Alagoas (UFAL).

4. Prof. da Disciplina de Patologia da Fundação Universitária de Ciências da Saúde de Alagoas Gov. Lamenha Filho (UNCISAL) / Escola de Ciências Médicas de Alagoas.

5. Cirurgião Oncologista da Seção de Cirurgia Oncológica da Santa Casa de Misericórdia de Maceió - AL.

Recebido em 19/08/2003

Aceito para publicação em 27/04/2004

Trabalho realizado no Serviço de Cirurgia Oncológica da Santa Casa de Misericórdia de Maceió e no Hospital Universitário da Universidade Federal de Alagoas. 


\section{INTRODUÇÃO}

O câncer gástrico é caracterizado como uma doença de acometimento mundial porém, de distribuição geográfica heterogênea e a segunda causa de óbito por câncer. ${ }^{1,2}$

A infiltração do tumor na parede gástrica, o comprometimento peritoneal, as margens da ressecção e a propagação linfática regional constituem fatores relacionados ao prognóstico ${ }^{3}$, porém, nem sempre os parâmetros prognósticos clássicos refletem o comportamento biológico tumoral, necessitando estudos de novos fatores prognósticos com o intuito de melhor entender os fenômenos biomoleculares. O recente crescimento do estudo de inúmeros marcadores biomoleculares como instrumento importante no estudo do câncer gástrico, trouxe como um dos seus elementos principais a proteína $\mathrm{p} 53$, à qual foi atribuída um papel significativo na carcinogênese.

A proteína p53 é codificada por um gene situado no cromossomo de número 17 , o qual, leva o mesmo nome (gene p53), em razão de seu peso molecular de $53 \mathrm{Kd}$. A sua principal função está relacionada à preservação da integridade do código genético em cada célula, ou seja, a manutenção da mesma sequiência de nucleotídeos ao longo da cadeia de toda molécula do DNA, igualmente presente em cada célula humana. ${ }^{4} \mathrm{~A}$ sua forma ativa (wild type) tem vida média muito curta (em torno de 6 minutos), devido à sua rápida degradação, o que torna extremamente difícil a sua detecção pelos métodos imunohistoquímicos. ${ }^{5}$ Ao contrário, as formas mutadas ou inativas, devido à maior estabilidade molecular $\mathrm{e}$ maior tempo de degradação, tendem a acumular-se no núcleo das células, permitindo que a expressão da proteína p53 seja usada como indicador indireto da mutação do gene p53. ${ }^{6,7}$ Durante o ciclo de divisão celular, a proteína p53 faz uma verificação quanto à eventual ocorrência de uma mutação na sequiência do código genético em decorrência de uma duplicação defeituosa do DNA. Caso seja verificada a existência de uma mutação, é função da proteína p53, através do desdobramento de uma cascata de reações, impedir que esta célula entre em processo de mitose e complete a divisão celular. Para isto, dois caminhos poderão ser seguidos: a correção da mutação através da ativação de proteínas de reparo ou a indução da morte celular através da apoptose. ${ }^{8,9}$

Por exercer esta função de detecção de alterações no DNA e conseqüente correção ou morte celular, a proteína p53 é considerada como uma guardiã do genoma, e é um importante elemento na prevenção do desenvolvimento de tumores, sendo seu gene codificador, classificado como gene supressor de tumor. ${ }^{5}$

A Proteína p53 detectada por imunohistoquímica é na maioria das vezes produto da mutação do gene p53, sendo indicador de pior prognóstico em carcinomas do cólon, pulmão e mama ${ }^{10,11}$. Entretanto, as características biológicas dos tumores são em geral determinadas pelas alterações genômicas ${ }^{12}$. O papel da expressão da proteína p53 como indicador prognóstico no câncer gástrico é controverso. ${ }^{13-18}$

Baseado nas razões acima referidas e o fato da literatura sobre o assunto ser escassa no Brasil e nula no estado de Alagoas, levou-nos a avaliar a significância prognóstica da expressão da proteína p53, sua correlação com fatores prognósticos clínicos e anatomopatológicos, tais como: idade, sexo, infiltração na parede gástrica “T”, grau de diferenciação histológica, tipo histológico de Laurén, estadiamento e comprometimento linfonodal em doentes portadores de adenocarcinomas gástricos submetidos a gastrectomias total e parcial.

Esta pesquisa foi aprovada pelas comissões de ética das instituições envolvidas, conforme resolução no 196/96 do Ministério da Saúde.

\section{MÉTODO}

Foram analisados os registros médicos e reestudadas as lâminas das peças cirúrgicas de 45 doentes portadores de adenocarcinomas gástricos submetidos a gastrectomias parcial e total, realizadas no período de janeiro de 1991 a maio de 2002 na Santa Casa de Misericórdia de Maceió e no Hospital Universitário da Universidade Federal de Alagoas. Foram excluídos os seguintes casos: 1 - os casos com metástases à distância (estádio IV), assim como, os casos com comprometimento da margem de ressecção tanto proximal quanto distal. 2 - os casos que evoluíram para óbito nos primeiros 30 dias de pós-operatório. 3 - os casos que evoluíram para óbito por outras causas que não o câncer gástrico e as suas complicações. 4 - os casos com história prévia de câncer. 5 os casos submetidos à tratamento químio e radioterápico e 6 - os casos nos quais os blocos da parafina não apresentavam condições para que se pudesse fazer o estudo imunohistoquímico. 


\section{Exame anatomopatológico}

1 - Primeira etapa (coloração pela hematoxilina-eosina): Através do exame microscópico foram feitos: A) avaliação do grau de diferenciação histológica, segundo a Organização Mundial de Saúde (1983), em bem, moderadamente ou pouco diferenciados e indiferenciados. Para efeito de análise, agruparam-se os tumores bem e moderadamente diferenciados em um grupo chamado de bem diferenciados e os tumores pouco diferenciados, uma vez que não houve casos de tumores indiferenciados, em outro grupo chamado de pouco diferenciados. B) avaliação do tipo histológico que segundo Laurén ${ }^{19}$, os tumores eram de padrão intestinal, difuso e os não classificados. C) avaliação da infiltração do tumor na parede gástrica (T). Seguiu-se a classificação proposta pela União Internacional Contra o Câncer $(1989)^{20}$. Também para efeito de análise os tumores T1 e T2 foram chamados de superficiais e os tumores T3 e T4 de profundos. D) avaliação do comprometimento linfonodal. Dividiu-se a amostra em dois grupos: positivo para a presença de metástases e negativo para a ausência de comprometimento linfonodal. E) avaliação do estadiamento. Seguiu-se o estadiamento da UICC $(1989)^{20}$. Na avaliação do parâmetro "N" deste estadiamento, seguiu-se o método descrito por Possik ${ }^{21}$, sendo os 45 casos subdivididos em dois grupos: inicial, que correspondeu aos casos de tumores com estadiamento $1 \mathrm{~A}$ e $1 \mathrm{~B}$; e avançado, que reuniu os casos com estadiamento $2,3 \mathrm{~A}$ e $3 \mathrm{~B}$.

2 - Segunda etapa (imunohistoquímica): Blocos de peças cirúrgicas de adenocarcinomas fixadas em formalina e embebidas em parafina foram selecionadas para exame imunohistoquímico pela técnica da Estrepto-Avidina-Biotina-Peroxidase com o anticorpo monoclonal mouse Anti-Human p53 Protein, clone DO-7 (Dako ${ }^{\circledR} \mathrm{A} / \mathrm{S}$ - Denmark). A técnica de imunohistoquímica já foi descrita anteriormente. ${ }^{22}$ Basicamente foram efetuados cortes histológicos de 3 micrômetros de espessura em lâminas previamente tratadas com 3-aminopropyl triethoxy silano (Sigma A - 3648 USA $^{\circledR}$ ) conforme protocolo do laboratório de patologia da Santa Casa de Misericórdia de Maceió-AL. O controle negativo foi processado sem o anticorpo primário e o controle positivo foi obtido de adenocarcinoma mamário que já sabidamente expressava níveis elevados da proteína p53.

\section{Avaliação da imunohistoquímica}

Utilizou-se para a contagem de 500 células, um microscópio óptico marca Leitz - Laborlux S, com aumento de 400 vezes, sendo realizado o exame por patologista da Santa Casa, sem conhecimento prévio da evolução dos doentes. A positividade para p53 foi considerada quando $20 \%$ ou mais das células, evidenciavam coloração nuclear - marron escuro. ${ }^{16,18}$

\section{Evolução ambulatorial}

O acompanhamento ambulatorial foi semestral, quando da marcação da consulta. Exames eram solicitados para a detecção de recidivas (endoscopia digestiva alta; radiografia do tórax e ultra-sonografia do abdome total). Os doentes que não compareciam aos controles, foram contactados por carta, por telefone e alguns até por visita médica domiciliar.

\section{Método estatístico}

A influência de cada variável na sobrevida dos doentes foi avaliada pelo teste estatístico de Mantel. ${ }^{23}$ As variáveis estatisticamente associadas com o desfecho desfavorável na análise univariada foram selecionadas para análise multivariada de Cox. ${ }^{24}$ A análise da associação entre fatores prognósticos e a positividade da 553 foi realizada pelo teste Qui-quadrado. Para hipótese de nulidade foi fixado $\mathrm{p}$ menor que $5 \%$ ou 0,05 . Foi colocado um asterisco $\left(^{*}\right)$ nos casos com significância estatística. O programa estatístico empregado para a análise das tabulações e frequiências foi o Epi Info ${ }^{\circledR}$, versão 2000 (Center for Disease Control and Prevention). Para as análises uni e multivariada, foi utilizado o programa SPSS ${ }^{\circledR}$, versão 6.0 .

\section{RESULTADOS}

Pacientes e características tumorais: Do total de 45 doentes, 27 eram do sexo masculino (60\%) e 18 do feminino (40\%). A média das idades foi 53,9 anos ( 26 - 75 anos), e mediana de 57 anos. Quarenta tumores $(88,9 \%)$ foram classificados como bem diferenciados e cinco $(11,1 \%)$ como pouco diferenciados. Quanto à infiltração na parede gástrica, 17 tumores $(37,8 \%)$ foram classificados como superficiais e 28 $(62,2 \%)$ como profundos. Em 20 doentes $(44,4 \%)$ havia comprometimento linfonodal e em $25(55,6 \%)$ os linfonodos estavam livres de doença. O estudo histológico revelou que 29 tumores $(64,4 \%)$ foram classificados como tipo intestinal e $16(35,6 \%)$ como tipo difuso de Laurén. O estadiamento TNM demonstrou que $12(26,7 \%)$ doentes apresentavam tumor inicial e $33(73,3 \%)$ tumores avançados.

Imunohistoquímica para p53: $\mathrm{Na}$ análise imunohistoquímica, 18 doentes $(40 \%)$ foram con- 


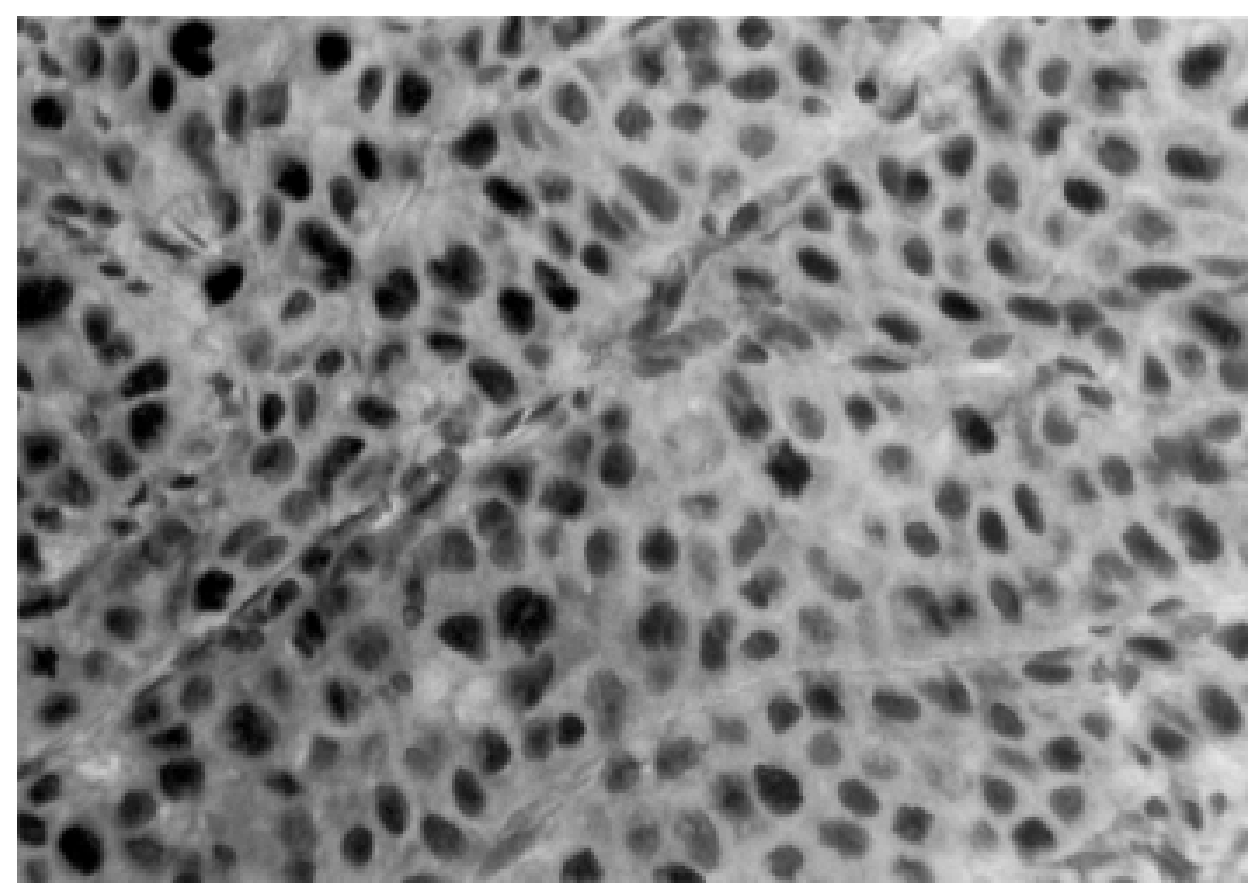

Figura 1 - Fotomicrografia de adenocarcinoma pouco diferenciado. Núcleos bem evidenciados pela imunohistoquímica para p53 (Estrepto-Avidina-Biotina-Peroxidade, 400x).

siderados positivos e $27(60 \%)$ negativos. A detecção imunohistoquímica da proteína p53 revelou um padrão variável de coloração, desde completamente ausente até distribuição difusa e com forte reatividade (Figura 1). Não se evidenciou associação estatística significativa entre a expressão da proteína p53 e as variáveis clínicas e anatomopatológicas estudadas.

Relação da expressão da p53 e a sobrevida: $O$ tempo de seguimento variou de 63 a 3920 dias, com média de 1020,4 dias e mediana de 798 dias. Trinta e um $(68,9 \%)$ doentes evoluíram para óbito. Dos $14(31,1 \%)$ doentes restantes, quatro $(8,9 \%)$ foram acompanhados durante cinco anos e $10(22,2 \%)$ acompanhados durante tempo variável inferior a cinco anos. As variáveis: idade, estadiamento, comprometimento linfonodal e infiltração tumoral na parede gástrica foram fatores prognósticos relacionados à sobrevida com significado estatístico $(\mathrm{p}<0,05)$, na análise univariada (Tabela 1). A análise estatística multivariada (Tabela 2) identificou apenas o comprometimento linfonodal como fator prognóstico independente.

\section{DISCUSSÃO}

Na casuística representada por 45 doentes portadores de adenocarcinoma gástrico, submetidos a tratamento cirúrgico na Santa Casa de Misericórdia e Hospital Universitário da Universidade Federal de Alagoas, 73,3\% foram classificados como estadiamento cirúrgico avançado, achado este, semelhante aos 78,9\% encontrado por Lourenço. ${ }^{25}$ Possik $^{21}$ analisando 301 doentes, observou somente 13,3\% de adenocarcinomas iniciais. Já no Japão, 65\% dos adenocarcinomas gástricos são do tipo precoce. ${ }^{26}$

A idade, a infiltração tumoral na parede gástrica, o comprometimento linfonodal e o estadiamento foram importantes quando analisados individualmente na sobrevida através da análise estatística univariada (Tabela 1). Nosso estudo mostrou uma significância estatística $(p=0,02)$ de pior prognóstico nos doentes com idade acima de 64 anos, como também observaram Kubota et al. e Popiela et al. . $^{27,28}$

O prognóstico mais favorável nos pacientes mais jovens pode ser explicado pelo melhor estado imunológico.

A infiltração tumoral na parede gástrica foi um dos principais fatores prognósticos, constatado neste estudo na análise univariada de sobrevida (Tabela 1), fato este, também verificado por Yokota et $a l .{ }^{29}$ Os adenocarcinomas quando invadem as camadas mais profundas da parede gástrica, atingem estruturas mais vascularizadas do ponto de vista hematológico e linfático havendo conseqüentemen- 
Tabela 1 - Avaliação univariada da influência dos fatores como idade, sexo, grau de diferenciação, tipo histológico de Laurén, infiltração da parede gástrica, comprometimento linfonodal, estadiamento e expressão da p53, em relação à sobrevida dos doentes com adenocarcinoma gástrico (Mantel).

\begin{tabular}{|c|c|c|c|c|c|}
\hline Variável & & $\mathbf{N}^{\circ}$ & Óbito(\%) & $\begin{array}{l}\text { Tempo Médio de } \\
\text { Sobrevida (dias) }\end{array}$ & $\mathbf{p}$ \\
\hline \multicolumn{6}{|l|}{ Idade } \\
\hline & $<64$ & 31 & 58,1 & 1713 & $0,0232 *$ \\
\hline & $>64$ & 14 & 92,9 & 847 & \\
\hline \multicolumn{6}{|l|}{ Sexo } \\
\hline & Masculino & 27 & 33,3 & 1508 & 0,2199 \\
\hline & Feminino & 18 & 72,2 & 1132 & \\
\hline \multirow{2}{*}{\multicolumn{6}{|c|}{$\begin{array}{l}\text { Grau de } \\
\text { Diferenciação }\end{array}$}} \\
\hline & & & & & \\
\hline & Bem & 40 & 67,5 & 1478 & 0,5770 \\
\hline & Pouco & 5 & 80 & 928 & \\
\hline \multicolumn{6}{|l|}{ Laurén } \\
\hline & Intestinal & 29 & 69,0 & 1488 & 0,9102 \\
\hline & Difuso & 16 & 68,9 & 1269 & \\
\hline \multicolumn{6}{|l|}{ Tumor } \\
\hline & Superficial & 17 & 41,2 & 2391 & $0,0136^{*}$ \\
\hline & Profundo & 28 & 85,7 & 951 & \\
\hline \multicolumn{6}{|c|}{ Linfonodos } \\
\hline & Positivo & 20 & 100 & 656 & $0,0000^{*}$ \\
\hline & Negativo & 25 & 44 & 2193 & \\
\hline \multicolumn{6}{|c|}{ Estadiamento } \\
\hline & Inicial & 12 & 16,7 & 3233 & $0,0013^{*}$ \\
\hline & Avançado & 33 & 87,9 & 886 & \\
\hline \multicolumn{6}{|l|}{ P53 } \\
\hline & Positiva & 18 & 66,7 & 1257 & 0,7942 \\
\hline & Negativa & 27 & 70,4 & 1467 & \\
\hline
\end{tabular}

A tabela 1 identifica as variáveis: estadiamento, idade, comprometimento linfonodal e infiltração na parede gástrica (T), como fatores prognósticos relacionados à sobrevida com significado estatístico $(p<0,05)$.

Tabela 2 - Análise multivariada dos fatores prognósticos (Cox).

\begin{tabular}{lcc}
\hline Variável & OD & p \\
\hline Linfonodo positivo & 5,02 & $0,0002^{*}$ \\
Idade $>$ 64 anos & 1,96 & 0,086 \\
Tumor profundo & 1,49 & 0,3907 \\
p53 positivo & 1,21 & 0,6367 \\
\hline
\end{tabular}

OD - Odds. $\quad$ * significância prognóstica.

A análise multivariada identificou o comprometimento linfonodal como único fator prognóstico independente que tenha influenciado a sobrevida dos doentes com adenocarcinoma gástrico ( $p=$ 0,0002). te uma maior probabilidade de disseminação metastática.

O comprometimento linfonodal é relatado como fator prognóstico independente em vários estudos. ${ }^{13,18,27,29-31}$. Em nosso estudo o comprometimento linfonodal foi fator prognóstico significativo na análise univariada (Tabela 1) e na análise multivariada, o comprometimento linfonodal foi o único fator prognóstico independente de sobrevida (Tabela 2).

Os pacientes com estadiamentos iniciais em nosso material $(26,7 \%)$, semelhantemente aos encontrados por Lourenço ${ }^{25}$, sobreviveram mais em relação aos casos de estadiamento avançado. Esta variável foi fator prognóstico de sobrevida em análise univariada. 
Nos últimos 20 anos o produto do gene p53, tem sido exaustivamente pesquisado. A análise laboratorial da proteína p53 pode ser realizada principalmente através da detecção sorológica de anticorpos circulantes anti-proteína p53 alterada e através da observação direta da proteína pela imunohistoquímica.

Foi utilizado neste estudo o método imunohistoquímico com o anticorpo monoclonal DO-7 que tem sido mais específico para a detecção da expressão da proteína p53 que os anticorpos $\mathrm{PAb}$ 1801 e o CM-1, segundo Baas et al ${ }^{32}$. Encontrouse expressão da proteína p53 em 18 casos de um total de 45 doentes (40\%). Este achado é compatível com expressões que variaram de $23 \%$ a $60 \%$ de pesquisadores que também utilizaram o mesmo anticorpo monoclonal DO-7, em peças cirúrgicas parafinadas e previamente fixadas em formalina a $10 \% .^{14,16,18,33-35}$

Percentuais que variaram de $34 \%$ a $57 \%$, utilizando o anticorpo policlonal CM-1, foram encontrados por vários pesquisadores. ${ }^{36-38}$

Estas variações encontradas na expressividade da proteína p53 poderá ser explicada pelos diferentes tipos de anticorpos utilizados e pela maneira como foi quantificada a positividade da reação. Por tratar-se de uma reação imunológica a recuperação do antígeno depende do estado de conservação dos blocos parafinados e adequadamente fixados em formalina tamponada. A demora na fixação do espécime cirúrgico ou uso de soluções inadequadas de formalina podem bloquear os sítios de ligação da proteína com o anticorpo, não permitindo a recuperação antigênica. Os anticorpos utilizados reagem em sítios específicos da proteína p53. Outro aspecto que deve ser considerado é que como a expressividade da reação para p53 reflete de maneira indireta a mutação no gene p53 e como temos estudos em doentes de países diversos não é difícil imaginar que poderemos estar avaliando tumores de padrão genético diferente.

No cotejo entre a expressão da proteína p53 e os demais fatores prognósticos estudados, nenhuma associação estatística significativa foi evidenciada, semelhante aos resultados encontrados por Mönig et al.; Liu et al. e Takeno et al. ${ }^{16,18,35}$

Neste estudo a expressão da proteína p53 também não foi fator prognóstico de sobrevida (Tabelas 1 e 2).
Outros pesquisadores utilizando anticorpos diferentes do que foi utilizado neste estudo, afirmam que a expressão da proteína p53 tem valor preditivo negativo na sobrevida dos pacientes operados de adenocarcinoma gástrico. ${ }^{36-38}$

As razões para estas variações nos resultados são desconhecidas. Uma possível explicação para falta de significância na sobrevida da expressão da p53 avaliada por método imunohistoquímico, poderá ser o fato da concordância entre a mutação do gene e o acúmulo da proteína não ser perfeita. $\mathrm{O}$ acúmulo da proteína p53 pode não necessariamente indicar a presença de mutação no gene e nem toda mutação no gene produz acúmulo da proteína p53. Adicionalmente, a proteína p53 (wild type) pode acumular no núcleo celular em resposta aos estímulos estressantes, tais como, dano ao DNA. Conseqüentemente a análise apenas da expressão da proteína p53 pode falhar em sua significância prognóstica.

Inconsistências nas análises da expressão da proteína p53 no adenocarcinoma gástrico como fator prognóstico isoladamente impedem a sua utilização na prática clínica. Estudos multicêntricos com padronização da técnica da imunohistoquímica e critérios na interpretação dos resultados poderão reduzir as variações encontradas. Muitas questões sobre a função da p53, as proteínas e sinais envolvidos nesta via, ainda não estão plenamente esclarecidas, necessitando que não apenas a proteína p53 e sim a sua investigação com outros marcadores desta mesma via ou não, possam resultar na identificação de doentes que se beneficiem de formas adicionais de tratamento, tais como, a terapia gênica com o uso de drogas que possam resgatar a função da proteína mutante ou mesmo outras formas de tratamento adjuntivo.

Por fim, os autores concluíram que: A) Quarenta por cento dos doentes analisados expressaram a reação pelo método imunohistoquímico (EstreptoAvidina-Biotina-Peroxidase); B) Não houve correlação estatística significativa entre a expressão da proteína p53 com as variáveis clínicas e anatomopatológicas (idade, sexo, grau de diferenciação, tipo histológico de Laurén, infiltração na parede gástrica, comprometimento linfonodal e o estadiamento TNM); C) A expressão da proteína p53 quando analisada individualmente e em conjunto com os demais fatores prognósticos, não se revelou fator prognóstico de sobrevida. 


\begin{abstract}
Background: To study the expression of p53 protein in gastric adenocarcinoma and its relationship to clinicopathological parameters such as, age, sex, infiltration of the gastric wall $(T)$, histological type of Lauren's classification, histological differenciation, lymph node involvement, stage (TNM) and patient longevity. Methods: Forty-five patients with the diagnosis of gastric carcinoma submitted to a sub-total gastrectomy or a total gastrectomy in the Surgical Oncology Department at the Santa Casa de Misericórdia Hospital in Maceió, Alagoas and the University Hospital of the Federal University of Alagoas, Brazil during the period of January 1991 to May 2002 were analysed.The expression of the p53 protein was evaluated by an immunohistochemistry method, and compared to age, sex, infiltration of the gastric wall, histological type, histological differenciation, lymph node involvement, stage (TNM) and patient longevity. Results: In the total number of patients, 27 were male (60\%). The age range of all patients was $26-75$ years (mean $=53.9$ years). Forty patients $(88.9 \%)$ were classified as well differenciated. As far as infiltration of the gastric wall, 28 patients $(62.2 \%)$ were classified as having deep infiltration. In 25 patients $(55.6 \%)$ the lymph nodes were free of disease. The histological study revealed that 29 patients (64.4\%) were classified as the intestinal type of Lauren's classification. The stage (TNM) showed that 33 patients (73.3\%) presented an advanced tumor. In the immunohistochemistry analysis, 18 patients (40\%) were considered positive.The follow-up varied between 63 to 3920 days, with the average time being 1020.4 days. The statistical method of univariate analysis of Mantel identified the variables: age, stage, lymph node involvement and the tumor infiltration of the gastric wall as prognostic factors related to the patient with a significant statistical longevity $(p<0.05)$. Multivariate analysis showed that only lymph node involvement was an independent prognostic factor. Conclusions: The author concluded that 18 (40\%) of the total number of 45 patients with gastric carcinoma showed an immunohistochemistry reaction. There was no significant statistical relationship between expression of p53 protein and prognostic factors studied. Expression of 53 protein was not an independent prognostic factor.
\end{abstract}

Key Words: Gastric adenocarcinoma; p53 protein; Immunohistochemistry; Prognosis.

\section{REFERÊNCIAS}

1. Corella D, Guillen M. Dietary habits and epidemiology of gastric carcinoma. Hepato-Gastroenterology 2001;48(42):1537-43.

2. Lambert R, Guilloux A, Oshima A, et al. Incidence and mortality from stomach cancer in Japan, Slovenia and the USA. Int J Cancer 2002; 20;97(6):811-18.

3. Gabbert HE, Meier S, Gerharz CD, et al. Incidence and prognostic significance of vascular invasion in 529 gastric cancer pacients. Int J Cancer 1991;49:203-7.

4. Soussi T, Legros Y, Lunbin R, et al. Multifactorial analysis of p53 alterations in human cancer : a review. Int J Cancer 1994;57:1-9.

5. Levine AJ, Momand J, Finlay CA. The p53 tumour suppressor gene. Nature 1991;351:453-6.

6. Finlay CA, Hinds PW, Tan TH, et al. Activating mutations for transformation by $\mathrm{p} 53$ produce a gene product that forms an hsc $700-$ p53 complex with an altered half - life. Mol Cell Biol 1988; 8:531-9.

7. Hall PA, Lane DP. p53 in tumour pathology: can we trust immunohistochemistry?- revisited!. J Pathol 1994;172:1-4.
8. Oren M, Rotter V. Introduction: p53 - the first twenty years. Cell Mol Life Sci 1999; 55:9-11.

9. Bullock AN, Feisht AR. Rescuing the function of mutant p53. Nature Rev Cancer 2001;1:68-75.

10. Starzynska T, Bromley M, Ghosh A, et al. Prognostic significance of $\mathrm{p} 53$ overexpression in gastric and colorretal carcinoma. Br J Cancer 1992;66:558-62.

11. Ribeiro UJR, Alves VA, Souza PMSB, et al. Correlação das proteínas p53 e KI-67 com o prognóstico de pacientes com adenocarcinoma de reto distal. Rev Bras Coloproct 2000; 20(4):248-56.

12. Kubicka S, Claas C, Staab S, et al. P53 mutation pattern and expression of c-erbB 2 and c-met in gastric cancer: relation to histological subtypes, helicobacter pylori infection, and prognosis. Dig Dis Sci 2002;47(1):11421.

13. Motojima K, Furui J, Kohara N, et al. Expression of p53 protein in gastric carcinomas is not independently prognostic. Surgery 1994; 116:890-5.

14. Victorzon M, Nordling S, Haglund $\mathrm{C}$, et al. Expression of P53 protein as a prognostic factor in Patients with gastric cancer. Eur J Cancer 1996;32 (2):215-20. 
15. Ichiyoshi Y, Oiwa H, Tomisaki S, et al. Overexpression of p53 is associated with growth pattern and prognosis in advanced gastric Cancer. Hepatogastroenterology 1997;44:546-53.

16. Mönig SP, Eidt S, Zirbes TK, et al. p53 Expression in Gastric Cancer: Clinicopathological Correlation and Prognostic Significance. Dig Dis Sci 1997;42 (12):246367.

17. Kaye PV, Radebold K, Isaacs S, et al. Expression of p53 and p21 waf1/cip1 in gastric carcinoma: lack of interrelationship or Correlation with prognosis. Eur J Surg Oncol 2000; 26:39-43.

18. Liu XP, Tsushimi K, Tsushimi M, et al. Expression of p21waf1/cip1 and p53 proteins in gastric carcinoma: Its relationships with cell proliferation activity an prognosis. Cancer Lett 2001(a);170(2):183-9.

19. Laurén P. The two histological main types of gastric carcinoma: diffuse and so-called intestinal type carcinoma: an attempt at a histoclinical classification. Acta Pathol Microbiol Immunol Scand 1965;64:31-49.

20. Hermanek P, Sobin LH. TNM Classificação dos tumores malignos. $4^{\mathrm{a}}$ ed. Rev. Trad. De H. Torloni, NW Motta, PE Pinto. Brasília: Centro de Documentação do Ministério da Saúde; 1989. p.43-6 [Estômago].

21. Possik RA. Fatores prognósticos de pacientes com adenocarcinomas de estômago submetidos à cirurgia radical: Análise multifatorial [Tese]. São Paulo: Faculdade de Medicina da Universidade de São Paulo; 1990.

22. Hsu SM, Raine L, Fanger H. Use of avidin-biotin peroxidase complex (ABC) in immunoperoxidase tecniques: a comparison between $\mathrm{ABC}$ and unlabelled antibody (PAP) procedures. J Histochem Cytochem 1981;29:577-80.

23. Mantel N. Evaluation of survival data and the new order statistics arising in its considerations. Cancer Chemoth Rep 1966;50:163-70.

24. Cox DR. Regression models and life-tables. J R Stat Soc 1972;34: 187-220.

25. Lourenço LG. Relação entre a contagem da microdensidade vasal tumoral e o prognóstico do adenocarcinoma gástrico operado [Tese]. São Paulo: Universidade Federal de São Paulo; 1997.

26. Kido S, Haruma K, Kitadai Y, et al. Changing pattern of gastric cancer in japan. In Siewert JD, Roder JD. Progress in gastric cancer research, 1997. Monduzzi, Bolongne. p. 37-42.
27. Kubota H, Kotoh T, Dhar DK, et al. Gastric resection in the Aged $(>=80$ years) with gastric carcinoma: A multivariate analysis of prognostic factors. Aust N Z J Surg 2000;70(4):254-57.

28. Popiela T, Kulig J, Kolodziejczyk P, et al. Long-term results of surgery for early gastric cancer. Br J Surg 2002;89(8):1035-42.

29. Yokota T, Kunii Y, Saito T, et al. Prognostic factors of gastric cancer tumours of less than $2 \mathrm{~cm}$ in diameter: rationale for limited surgery. Eur J Surg Oncol 2002;28:209-13.

30. Siewert JR, Böttcher K, Stein HJ, et al. Relevant prognostic factors in gastric cancer: ten- year results of the German Gastric Cancer Study. Ann Surg 1998;228 (4): 449-61.

31. Inoue K, Nakane Y, Iiyama H, et al. The Superiority of ratio-based lymph node staging in gastric carcinoma. Ann Surg Oncol 2002;9(1):27-34.

32. Baas IO, Mulder JWR, Offerhaus GJA, et al. An evaluation of six antibodies for immunohistochemistry of mutant P53 gene product in archival colorectal neoplasms. J Pathol 1994;172:5-12.

33. Craanen ME, Blok P, Dekker W, et al. Chronology of p53 protein accumulation in gastric carcinogenesis. Gut 1995;36: 848-52.

34. Lim BHG, Soong R, Grieu F, et al. p53 accumulation and mutation are prognostic indicators of poor survival in human gastric carcinoma. Int J Cancer 1996;69: 200-4.

35. Takeno S, Noguchi T, Kikuchi R, et al. Analysis of the survival period in respectable stage IV gastric cancer. Ann Surg Oncol 2001; 8 (3):215-21.

36. Martin HM, Filipe MI, Morris RW, et al. p53 expression and prognosis in gastric carcinoma. Int $\mathbf{J}$ Cancer 1992;50:859-62.

37. Díez M, Medrano MJ, Gutierrez A, et al. p53 protein expression in gastric adenocarcinoma. Negative predictor of survival after postoperative adjuvante chemotherapy. Anticancer Research 2000;20:3929-34.

38. Roviello F, Marrelli D, Vindigni C, et al. p53 accumulation is a prognostic factor in intestinal-type gastric carcinoma but not in the diffuse type. Ann Surg Oncol 1999; 6(8):739-45.

Endereço para correspondência:

Frederico Theobaldo Ramos Rocha.

Rua Rubens Canuto 234, apt. 502

Edf. Tarumã, Ponta Verde, Maceió - AL. CEP: 57035 - 200.

E-mail: rochafrederico@uol.com.br 